\title{
Critical considerations in responding to crystal methamphetamine use in Australian Aboriginal communities
}

\section{Running title: Ice use in Australian Aboriginal communities}

Sarah MacLean ${ }^{1,2}$, Ross Hengsen ${ }^{3}$, Raelene Stephens ${ }^{3}$

${ }^{1}$ Department of Allied and Community Health, La Trobe University, Melbourne, Australia

${ }^{2}$ Centre for Health Equity, The University of Melbourne, Melbourne, Australia

${ }^{3}$ Mallee District Aboriginal Services, Mildura, Australia

Sarah MacLean BA(Hons), MA, PhD, Senior Lecturer, Department of Allied and Community Health and Senior Research Fellow, Centre for Health Equity, Ross Hengsen, Dip Counselling \& OHS, Bringing Them Home Counsellor, Raelene Stephens SRN SRM BAppSc, Social and Emotional Wellbeing Manager. Correspondence to Dr Sarah MacLean, Department of Allied and Community Health, La Trobe University, Bundoora, Vic 3086, Australia. Tel: +61 3 94892520 / 0418778081. Email: S.MacLean@latrobe.edu.au

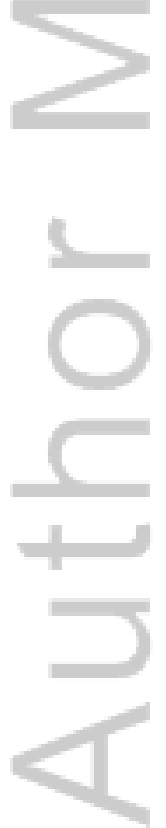

This is the author manuscript accepted for publication and has undergone full peer review but has not been through the copyediting, typesetting, pagination and proofreading process, which may lead to differences between this version and the Version of Record. Please cite this article as doi: $10.1111 /$ dar.12468 


\section{Abstract}

Introduction and aims: This article identifies factors that participants in a study based in an Australian regional centre believed to be critical to understanding and responding to crystal methamphetamine (ice) use among Aboriginal people. Design and methods: The study entailed a participatory methodology involving a university and an Aboriginal community controlled organisation. Semi-structured interviews conducted with ice users $(n=14)$, family members $(n=6)$ and workers $(n=6)$ were analysed thematically. Results: Interviewees believed that historical trauma, contemporary disadvantage and racism cohere to produce a market for ice and other drugs within Aboriginal communities. Intense shame prevented some ice users and their families from seeking help, while fear about ice use was exacerbated when suppliers of ice threatened violence. Disconnection from family and community further intensified a sense of isolation and despair. By contrast, family reintegration provided ice users in the study with the strongest motivation for change. Discussion and Conclusions: Although drawing only on a small sample of participants, the study suggests that Aboriginal people's experiences of ice use may have some distinct characteristics, meaning that tailored responses are required. Interventions should address the shame and ameliorate the fear that surround problematic ice use for families and users, provide help to those who feel trapped due to drug debts and relationships with dealers, and support families to maintain contact with ice users where this is manageable. Supports for users to remain connected to family and community are also critical. The effectiveness of family wellbeing interventions as adjuncts to treatment could be evaluated.

Key words: Methamphetamine; Health Services, Indigenous; Primary Prevention; Secondary Prevention; Tertiary Prevention; Shame 


\section{Introduction}

Use of the drug known as 'ice' (crystal methamphetamine) has generated increasing concern in both Aboriginal and non-Indigenous communities across Australia in recent years, as it is associated with significant health, social and economic harms [1]. Although relatively expensive in Australia, ice still appears to be widely available and accessible [2].

Despite the talk in the media of an 'ice epidemic', a national Australian survey conducted in 2013 showed that only around two percent of the population had used meth/amphetamine over the previous year [3]. While the prevalence of methamphetamine use in the general Australian population has remained stable over the past decade, a greater proportion of people are now using ice than any other form of methamphetamine $[3,4]$. The purity of ice also appears to have increased since 2010 [2].

Methamphetamine use seems to be more prevalent among Aboriginal than non-Indigenous Australians [5], particularly in urban and regional areas [6]. Recent reports indicate that ice is also now used in some remote Aboriginal communities [7]. Regional Victorian communities, such as Mildura, have experienced increases in ambulance call-outs for patients affected by methamphetamine [8].

Very little evidence of treatment and intervention outcomes for Aboriginal methamphetamine users is available [9]. Studies involving methamphetamine users in the mainstream population indicate that some psychological and residential treatments are effective in the short term [10-13]. However, it is unclear how long people participating in these treatments are able to maintain positive changes or whether these treatments are similarly effective for Aboriginal people. A government inquiry [14] found that ice users (IU) 
often require longer and more intensive treatment than other drug users. As such, the inquiry recommended further research into the treatment and intervention needs of specific groups including Aboriginal people and those living in regional areas.

Most of the literature on the specific needs of Aboriginal people who use ice is restricted to documents from government inquiries, and submissions to these inquiries by Aboriginal organisations $[14,15]$. A small qualitative research project conducted in New South Wales explored Aboriginal people's experiences of ice use [16]. Similarly, a community publication generated from our study in Mildura offers specific recommendations for local interventions [17].

This article draws on interviews with Aboriginal people who used or had used ice, family members (FM) of IUs and workers with professional contact with Aboriginal IUs in Mildura. Its purpose is to inform future service responses by identifying factors that influence ice use for Aboriginal people and their communities, and which are also important considerations in designing treatment and interventions. We use the term 'Aboriginal' to refer to all Australian Indigenous peoples, both Torres Strait Islander and Aboriginal, except where we refer to a reference or quote where another term, usually 'Indigenous', is used.

\section{Method}

\section{Design and approach}

The project was conducted as a collaboration between the [deleted for review] and Mallee District Aboriginal Services (MDAS), an Aboriginal community controlled health service 
located in Mildura. Mildura is approximately 550 kilometres north-west of the capital city of Melbourne.

The research approach was participatory [18] in that it was conducted by university researchers working closely with MDAS staff who themselves had frequent contact with IUs. A project agreement developed prior to commencing the research reflected consultations between the two agencies over a range of aspects of the study. The research was overseen by a reference group comprising staff from MDAS and the University of Melbourne. It was approved by the Human Research Ethics Committee at the University of Melbourne.

MDAS staff developed research questions collaboratively with SM, a university-based researcher. The majority of the interviews were conducted by an Aboriginal MDAS staff member $(\mathrm{RH})$. MDAS held a community forum to disseminate study findings in September 2015.

\section{Sampling procedure}

IUs and their families are a difficult population to reach and hence participants were accessed using convenience sampling. Potential participants were informed of the study by MDAS staff, who then introduced those who expressed interest to the research team. We made efforts to include both men and women in the study. Workers were sampled to reflect the perspectives of various agencies in Mildura involved in the treatment and policing of IU.

\section{Study participants}

Fourteen IUs and ex-IUs were interviewed. Given the proclivity of IUs to relapse, and the small sample size of the study, we do not generally distinguish between current and past 
users. Participants were aged between 18 and 49. Nine were male (M), with the remaining five female (F), and 12 had attended an alcohol and drug service. The time that had elapsed since they had used ice varied from a few days to 12 months. All except one were, or had been, poly-drug users.

The six FMs in the study included one ex-partner, two parents and three siblings. Half were male, and all but one identified as Aboriginal. Two FMs were also professional workers in Mildura, but elected to be asked about their own familial involvement with ice users.

The final group of interviewees were six employees of agencies providing services to Aboriginal IU. Of these, four had direct contact, with two employed as managers. Half of the workers involved were male and half were Aboriginal.

Interview procedure

Interviews were semi-structured, with researchers encouraging participants to share accounts of their experiences. They lasted from between half an hour to an hour. Theme sheets were developed for each set of participants to ensure that interviews covered core issues, i.e. experiences of using ice, effects of ice use on their lives, and where they had sought help. Participants were offered a choice of being interviewed alone, or with a family member or colleague. For example, one IU and his brother were interviewed together. In total, 23 interviews were conducted during late 2014 and early 2015. All participants gave consent for their comments to be audio recorded.

\section{Analysis}


Interviews were initially coded [19] by SM in descriptive subject areas using the software package NVivo 10 to identify comments made by participants about how Aboriginal people were affected by ice use and the interventions they regarded as most likely to work within Aboriginal communities. As the analysis developed through discussions between the authors (two of whom were MDAS staff), three overarching themes emerged. These were: historical trauma and contemporary disadvantage; shame and fear; and disconnection and connection. Data were recoded [20] in accordance with these themes, which are reported on here.

\section{Historical trauma and contemporary disadvantage}

IUs in our research identified reasons for commencing ice use that were not dissimilar to the explanations given by non-Indigenous users [21, 22]. For example, one interviewee remembered the strength of the rush as the reason he moved to ice from other amphetamines: 'it's real intense these days' [IU 1: M]. They described using ice to enhance their enjoyment of social events, and to improve their energy levels and ability to accomplish tasks. However, as reported elsewhere [14], many participants emphasised that Aboriginal people were very likely to have grown up in families suffering from the long-term effects of historical dispossession and punitive social policies [23], and to have experienced trauma themselves though familial conflict, substance use and other problems. Along with racism, which also impacted on their aspirations for life, these experiences made them susceptible to craving the positive sensations and feelings they experienced when using ice: 
There hasn't been sufficient healing in their lives. You know, like lots of people, they've had trauma and I know all, all sectors of society have trauma but I do think that there is more trauma in young Aboriginal people, young Aboriginal children. (IU 5: M)

Like [drug use is] sort of like it's more acceptable in an Indigenous community to do it because you, you watched Elders do it, you watch your parents do it. Like how are you supposed to want to stop or know how to stop when you've got your Elders and that all sitting there doing what you're doing but telling you not to do it? (IU 6: M)

= Well everyone thinks black fellas [use ice], so I might as well do it. (IU 7: F)

Participants suggested that poverty and trauma also impeded the capacity both of the Aboriginal community and of families to deal with members' ice use. Some believed that the community as a whole felt overwhelmed and powerless to do anything about ice.

The lack of social opportunities within regional communities also increased the appeal of ice use. As one participant explained, young Aboriginal people often feel uncomfortable in mainstream social institutions, even in shops and cafes, which meant that few recreation options were available to them. Using ice with friends in private settings was therefore particularly appealing:

And I guess [we need] more social things for kids to do, especially in broader communities. It's easier to get ice than it is to, I don't know, walk into a shop for Indigenous kids. (IU 12: M)

Aboriginal Australians are more likely to be unemployed than non-Indigenous Australians [24]. Selling ice provided both an income and ready access to the drug. Motorcycle gangs or 'bikies' are active in Mildura and other regional centres [2]. Interviewees repeatedly described how bikies capitalise on Aboriginal people's social disadvantage by aggressively marketing ice to them and encouraging them to commence dealing. Because of their close

This article is protected by copyright. All rights reserved. 
community connections, Aboriginal people were able to facilitate rapid access to ice new users. Bikies and other dealers reportedly greeted people leaving jail with samples of ice to ensure they maintained their dependence:

How I see it is Aboriginals are the biggest people that get affected by it easily. There's bikies coming into our towns and they work off these young ones and then the young ones are getting around lost. Everyone loses their spirit because their children are walking around, don't know what to do. (IU 13: F)

\section{Shame and fear}

An ice user and his brother, interviewed together, vividly described the sense of shame that they carry as young Aboriginal people:

\section{IU 12: Because Indigenous kids carry shame. I carry shame myself... That's how} the Indigenous, especially the younger community, that's how they, they sort of, they feel judged.

FM 4: We were led to believe we were the wrong kind of people.

While some people use ice without becoming dependent [26] our small group of research participants spoke of their very regular drug use and its acute impacts on themselves and on their families. As people's ice use intensified they often became involved in crime or sex work to fund their habit, magnifying the shame about themselves alluded to above. Accounts of family violence perpetrated by IUs, and the removal of children by child protection authorities, were common. One woman told us that her children were not safe in her care when she was coming down from ice: 'I just wanted to hurt them when I wasn't on it, when I was coming down. I couldn't have my kids around me' (IU 14: F). IUs felt that they had failed in their most important life roles - as parents and partners, as siblings, and as sons and daughters. Another woman reflected on her family's disgust at her drug use: 
You lose your family. I've lost most of me family. They look at you, dirty, you

know, they look at you different. More disgusted (IU 10: F)

Although ice use was widespread within their social circles, participants argued that when it precipitated violence or crime, particularly involving Aboriginal victims, it was viewed very negatively within the Aboriginal community. Once gained, a reputation as a problem IU was hard to shake off. Stories about crimes committed by IUs travelled quickly through the community, becoming embellished through retelling:

But with the Aboriginal community everyone knows everyone. We all know the same people in some way and they hear something, then they tell everybody else and then by the time it gets back to you you're the worst person in the world... And you only like take, pinch $\$ 20$ from someone's purse, and you end up [having a reputation for] robbing a bank at the end of it. (IU 4: M)

It was not unusual for users and ex-users to try to hide their ice use from doctors and other health care providers due to the shame associated with it. Family members of IUs also identified shame and fear of disclosure about the ice use in their family as reasons not to access services themselves.

The violence associated with ice use exacerbates the fear about the drug [14]. Although not restricted to the Aboriginal community, this was mentioned many times during our research. Families feared violence from IUs. Users feared violence from drug dealers, generally members of bikie gangs, who threatened retribution when they failed to pay money owed, extort drug debt money from others or when they expressed a wish to stop dealing ice. One IU (13: F) described how she was warned that she would be given a 'boot ride' (being forced into a car boot) by dealers if she didn't commit an assault to replace 
missing drugs. A FM (5: F) said that her brother was made to dig holes - a warning as to where he could end up he did not comply with bikies' demands.

A few participants suggested that, mindful of the centrality of family for many Aboriginal people, bikies had threatened to harm their patents, spouses or children. One IU said that he had contemplated suicide because he had felt that there was no escape from working for bikies, with the family member referred to above recounting a similar story about her brother. Participants noted that threats of violence to ice users and their families had been implicated in the suicides of local young Aboriginal people in the community.

Another source of fear is the reputation of ice as the worst of all drugs, both within the Aboriginal community and more widely. Interviewees commented on the advertisements about ice use that they saw on television, with some reporting that these left them with little hope their relative could be helped.

\section{Disconnection and connection}

People in the research spoke about commencing ice use because they enjoyed the social experience of using with other people. A family members suggested that people who were isolated and 'needed to belong somewhere' [FM 5: F] were particularly vulnerable to recruitment by networks of dealers. Yet IU also described feeling profoundly isolated as their drug use intensified. An ex-user explained how difficult it was to be around others when she was using ice, contrasting this with her current more socially engaged sense of self: 
I was in my shell. Walked around with my hoodie on all the time and I couldn't even look anyone in the eyes and have a proper conversation with them... I'd be just death staring like I'm ready to kill. I can't talk. I'm ready to go. I can't be round these people. That was me. And since my recovery I feel I can do that now and have a proper conversation with people and talk to them and not wearing a hood to feel secure. Feel good about myself and now I've got an open mind and I can think. (IU 14: F)

Disconnected from family as a result of things they had done when ice affected was deeply painful: 'You are already contemplating suicide before you realise this has tore your family apart, tore you from your friends' [IU 1: M]. A woman argued that due to a risk of suicide, families should keep drug users close and avoid judging them:

The best thing I reckon a family member should do is... don't ever judge because it could lead the wrong way and the other person can really do something. Like ... when you're coming down off the ice, you feel like some people want to kill their selves. They're feeling no love for their selves. They feel really empty inside and really sad. And when you don't get that support from any family you really do feel let down. And you're empty inside and there's no way of stopping using drugs because no one cares about you. (IU 10: F)

While users spoke of the shame and grief they felt at the damage their use had caused to family relationships, the overwhelming motivation to stop ice use among interviewees was a desire to reconnect with family. Family was mentioned time and time again as the main reason for stopping ice use and remaining abstinent, particularly to recover children and repair relationships with spouses. Families were also the most valuable resource that people had to help them take back control of their lives and change patterns of drug use. Participants emphasised that most Aboriginal people had access to some support within the community:

We are a family people; you know what I mean? Because they're using [ice], instead of pushing them away, we should, you know, cradle them in a bit more and give them that incentive to get away from it. (IU 2: M) 
There's always support whether [it's] your, like, second cousins or distant relations but there is always support within the community. (IU 12: M)

Well, like I mean my cousin... like she's in my head all the time, you know. She's always praising me and stuff like that [for not using ice]. You know, to hear that come out of one of your family's mouth (IU 1: M)

While ice users wanted to engage more closely with families, family members of ice users whom we spoke with reported exhaustion from dealing with relatives who used ice and other drugs. Particularly when their ice-using relatives were violent, it was almost impossible to maintain close contact. This was a source of grief and despair, and families felt that little support was available to them.

The capacity to develop a sense of connection was regarded as critical to people's capacity to access and engage with services. The workers we interviewed noted that Aboriginal people often disliked attending residential services that were far away from their community. Both IU and FM believed they were more likely to be understood by Aboriginal staff and to meet others they could connect with at Aboriginal services, although some were concerned that Aboriginal treatment providers might disclose their drug use to the community:

- Obviously an Indigenous organisation, yeah, there [are] other black fellas that don't want to [use ice] like I don't want to do it... When it's people of similar like issues to what you face it's easier to connect and like, you know, get that understanding that they do want to help. (IU 7: F)

An Indigenous person sometimes don't want to come to [an Aboriginal service] because of the other Indigenous people... And they don't trust the confidentiality about it. And then you've got mainstream where they think that they don't relate to them. So at least if you come [to MDAS] and you've got Indigenous staff, you're going to have a connection. (FM 3: F) 
Participants emphasised the importance of making opportunities for social connection available for people who were trying not to use drugs. Providing treatment for individuals, and then returning them to the contexts in which they previously used ice and other drugs, leaves them at high risk of relapse [25]. Programs that would help people connect to culture and to Country were seen as important here:

\section{Bringing them back to their cultural connection, you know, having a cultural safety plan for what they're trying to achieve and their goals. (FM 3: F) \\ If you lose something towards your culture and identity, well then of course you're going to use more drugs. (IU 14: F)}

\section{Discussion and Conclusions}

This study reports on the experiences of only a small sample of research participants, however our findings are consistent with the documented experiences of Aboriginal IUs in other parts of Australia [14-16]. In interpreting our study, it should be borne in mind that participants were recruited through a health service, and hence the problems they discussed tended to be serious. The perspectives of Aboriginal people whose use of ice is more controlled are not reflected here.

It is, of course, unlikely that all Aboriginal people will experience ice use in the same way, or that their experiences will be completely different to those of non-Indigenous users. Some accounts of increasing dependence and isolation, violence and suicidality as people's drug use intensified were similar to those provided by non-Indigenous IU in other research [1, 14]. Aspects of the process of seeking treatment also resembled those described by nonIndigenous users, such as long waiting times to access services [14]. 
Nonetheless, study participants shared compelling accounts of disadvantage and trauma, shame and fear, and disconnection and connection that they argued were linked in part to their Aboriginality. This suggests that some Aboriginal people's experiences of ice use may have distinct characteristics specific to their community and that, as a corollary, tailored responses are required.

The suffering and trauma that Aboriginal people have experienced, and continue to endure, has its roots in policies enacted by successive governments, notably the forced separation of children from their families [23]. It is impossible to ameliorate this though alcohol and drug treatment interventions alone. Along with unemployment and a lack of available life options, such familial and individual trauma coheres to produce a lucrative market for ice within some Aboriginal communities, a market that dealers have exploited malevolently. This highlights the importance of taking a comprehensive approach to Aboriginal health, one that includes family and community strengthening and providing employment and educational opportunities. Participants argued that connecting young people to family and community would strengthen their identities as Aboriginal people and make ice use less appealing. It is important, too, that a focus on ice does not detract attention from other pressing issues such as alcohol and tobacco misuse [27].

This study supports recommendations in existing guideline documents which advise on treatment for Aboriginal people who use drugs, endorsing collaborative, culturally sensitive and family inclusive approaches [see, for example, 28, 29]. Consistent with this, strategies to support families to maintain contact, wherever possible, with relatives who use ice should be central to any overall response. Findings from the study also support an ongoing need for treatment and intervention programs that are run for and by Aboriginal people who can 
connect with IU and their families. After-care services to support people returning home from jail or treatment are also critical, as is availability of recreation options for people who want to remain abstinent from ice use.

A substantial body of literature identifies shame as a legacy of historical trauma and dispossession for Indigenous people both in Australia and other colonised countries [31, 32]. Ice and other drug use contribute to this heavy burden for individuals and their families, causing immense distress and impeding people from seeking help. As such, any interventions must incorporate strategies that alleviate shame that surrounds ice use. It is particularly important for media campaigns about ice use not to inadvertently exacerbate shame and fear by implying that ice use is so dehumanising that nothing can be done for those affected.

Reducing the supply of ice will remain challenging. This study documents accounts of bikie gangs targeting Aboriginal people in one regional centre to encourage them to use and sell ice, and subsequently making threats of violence to ice users and their family members. Users spoke becoming so desperate as to contemplate suicide, with some identifying these threats as part of what led people to feel that suicide was their only option. Accessible and effective support must be available to Aboriginal people who fear retribution for failing to pay drug debts or for refusing to comply with dealers' demands. It may be useful to share stories of entrapment and coercion at the hands of dealers, and of the suppliers who profit from the work of ice dealers, to deter Aboriginal people from engaging with them.

The centrality of family to recovery from ice use and the corresponding difficulties reported by family members in coping with ice-using relatives suggests that family strengthening 
interventions may be useful adjuncts to alcohol and drug treatment. For example, the Family Wellbeing Program has been shown to improve outcomes for Aboriginal participants on a range of health and wellbeing measures [30]. The program could be trialled and evaluated to identify whether it enhances people's capacity to manage the problems and conflicts that underlie drug use and exacerbate the difficult of caring for drug using relatives.

\section{Acknowledgments}

This study was funded by the Melbourne Social Equity Institute at the University of Melbourne and SM's work was supported by a fellowship from VicHealth. We thank Professor Kerry Arabena for advice on the project, MDAS staff for facilitating interviews and the interview participants for sharing their experiences.

This article is protected by copyright. All rights reserved. 


\section{References}

1. Watanabe-Galloway S, Ryan S, Hansen K, Hullsiek B, Muli V, Malone AC. Effects of methamphetamine abuse beyond individual users. J Psychoactive Drugs 2009;41:241-8.

2. Australian Crime Commission. The Australian methylamphetamine market: The national picture. Canberra: Commonwealth of Australia, 2015.

3. Australian Institute of Health and Welfare. National Drug Strategy Household Survey detailed report: 2013. Canberra: Australian Institute of Health and Welfare (AlHW), 2014.

4. Lim MSC, Cogger S, Quinn B, Hellard ME, Dietze PM. 'Ice epidemic'? Trends in methamphetamine use from three Victorian surveillance systems. Aust N Z J Public Health 2015;39:194-5.

5. - Australian Institute of Health and Welfare. 2010 National Drug Strategy Household Survey report. Canberra: AlHW, 2011

6. Australian Bureau of Statistics. 4727.0.55.001 - Australian Aboriginal and Torres

Strait Islander Health Survey: first results, Australia, 2012-13, 2013-17 February 2015.

Available at:

http://www.abs.gov.au/ausstats/abs@.nsf/Lookup/4727.0.55.001Chapter3002012-13 (accessed October 2015).

7. Clough A, Fitts M, Robertson J. Recent warnings of a rise in crystal methamphetamine (" ice") use in rural and remote Indigenous Australian communities should be heeded. Med J Aust 2015;203:19.

8. Lloyd B, Matthews S, Gao CX. Trends in alcohol and drug related ambulance attendances in Victoria: 2012/13. Fitzroy, Victoria: Turning Point, 2014.

9. MacLean S, Harney A, Arabena K. Primary health-care responses to methamphetamine use in Australian Indigenous communities. Aust J Prim Health 2015;21:384-90.

10. Ciketic S, Hayatbakhsh MR, Doran CM, Najman JM, McKetin R. A review of psychological and pharmacological treatment options for methamphetamine dependence. Journal of Substance Use. 2012;17:363-83.

11. Lee NK, Rawson RA. A systematic review of cognitive and behavioural therapies for methamphetamine dependence. Drug Alcohol Rev 2008;27:309-17.

12. Mcketin R, Najman JM, Baker AL, et al. Evaluating the impact of community-based treatment options on methamphetamine use: findings from the Methamphetamine Treatment Evaluation Study (MATES). Addiction 2012;107:1998-2008.

13. Mcketin R, Dunlop AJ, Holland RM, et al. Treatment outcomes for methamphetamine users receiving outpatient counselling from the Stimulant Treatment Program in Australia. Drug Alcohol Rev 2013;32:80-7.

14. Law Reform Drugs and Crime Prevention Committee. Inquiry into the Supply and Use of Methamphetamines, particularly 'Ice', in Victoria - Final report. Melbourne: Parliament of Victoria, 2014.

15. Queensland Aboriginal and Islander Health Council. QAIHC options paper responding to the National Ice Taskforce. Brisbane: QAIHC, 2015.

16. Blue Moon Research and Planning \& Australia, Department of Health and Ageing. Patterns of use and harms associated with specific populations of methamphetamine users in Australia - exploratory research: qualitative research report. Canberra: Department of Health and Ageing, 2008. 
17. MacLean S, Hengsen R, Stephens R, Arabena K. Supporting the Mildura Aboriginal Community's Response to Ice use. Melbourne: Onemda VicHealth Group, The University of Melbourne, 2015.

18. Bergold J, Thomas S. Participatory research methods: a methodological approach in motion Historical Social Research / Historische Sozialforschung. 2012;37:191-222.

19. Huberman AM, Miles MB. Data management and analysis methods. In: Denzin NK, Lincoln YS, eds. Handbook of qualitative inquiry. Thousand Oaks: Sage, 1994:428-44.

20. Wolcott HF. Transforming qualitative data: description, analysis, and interpretation. Thousands Oaks, CA: Sage, 1994.

21. Sherman SG, German D, Sirirojn B, Thompson N, Aramrattana A, Celentano DD. Initiation of methamphetamine use among young Thai drug users: a qualitative study. J Adolescent Health 2008;42:36-42.

22. Lee JC, Nakama H, Goebert D, Alicata D. Gender differences in reasons for methamphetamine use in an ethnically diverse population in Hawaii. Journal of Substance Use 2015;20:93-6.

23. Human Rights and Equal Opportunity Commission. Bringing them Home: Report of the National Inquiry into the Separation of Aboriginal and Torres Strait Islander Children from their Families. Canberra: Australian Human Rights Commission, 1997.

24. Commonwealth of Australia. National Aboriginal and Torres Strait Islander Health Plan. Canberra: Australian Government, 2013.

25. Brecht $M-L$, Herbeck D. Time to relapse following treatment for methamphetamine use: a long-term perspective on patterns and predictors. Drug Alcohol Depend 2014;139:1825.

26. Wallace C, Galloway T, McKetin R, Kelly E, Leary J. Methamphetamine use, dependence and treatment access in rural and regional North Coast of New South Wales, Australia. Drug Alcohol Rev 2009;28:592-9.

27. Harley F, Forbes C, Cordoma L. Project Ice Mildura: Evaluation of the community campaign measuring reach and impact. Mildura: The Vinson Centre for Applied Social Research, 2014.

28. Gray D, Stearne A, Wilson M, Doyle M. Indigenous-specific alcohol and other drug interventions: continuities, changes and areas of greatest need. Australian National Council on Drugs: National Drug Research Institute, Curtin University, 2010.

29. Lee K, Freeburn B, Ella S, Miller W, Perry J, Conigrave K, eds. Handbook for Aboriginal alcohol and drug work. Sydney: University of Sydney, 2012.

30. Whiteside M, Tsey K, Cadet-Jones Y, McCalman, J. Promoting Aboriginal Health: The Family Wellbeing Empowerment Approach. Cham Heidelberg New York Dordrecht London: Springer,2014.

31. Mohatt NV, Thompson AB, Thai ND, Tebes JK. Historical trauma as public narrative: A conceptual review of how history impacts present-day health. Soc Sci Med 2014;106:128-

36.

32. Treloar C, Jackson L, Gray R, Newland J, Wilson H, Saunders V, et al. Multiple stigmas, shame and historical trauma compound the experience of Aboriginal Australians living with hepatitis C. Health Sociology Review. in press. 




This article is protected by copyright. All rights reserved. 


\section{University Library}

\section{- M M N E R VA A gateway to Melbourne's research publications}

Minerva Access is the Institutional Repository of The University of Melbourne

Author/s:

MacLean, S;Hengsen, R;Stephens, R

Title:

Critical considerations in responding to crystal methamphetamine use in Australian Aboriginal communities

Date:

2017-07-01

Citation:

MacLean, S., Hengsen, R. \& Stephens, R. (2017). Critical considerations in responding to crystal methamphetamine use in Australian Aboriginal communities. DRUG AND ALCOHOL REVIEW, 36 (4), pp.502-508. https://doi.org/10.1111/dar.12468.

Persistent Link:

http://hdl.handle.net/11343/291833 